\title{
Management of ischemic necrosis after posteromedial release of clubfoot
}

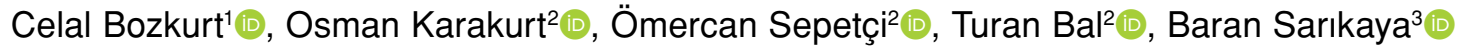 \\ ${ }^{1}$ Department of Orthopedics and Traumatology, Health Sciences University, Gaziosmanpaşa Training and Research Hospital, Istanbul, Turkey \\ ${ }^{2}$ Department of Orthopedics and Traumatology, Harran University Faculty of Medicine, Şanlıurfa, Turkey \\ ${ }^{3}$ Department of Orthopedics and Traumatology, Health Sciences University, City Hospital, Bilkent, Ankara, Turkey
}

Ponseti method is the gold-standard treatment method for de novo, neglected, and recurrent clubfoot disease. ${ }^{[1]}$ However, some neglected and recurrent diseases do not respond to Ponseti treatment and several surgical attempts are needed according to deformity. Deficiency of the anterior tibial artery and dorsalis pedis artery has been reported in 6.7 to $86 \%$ of the clubfoot patients. ${ }^{[2]}$ This arterial deficiency may cause hypoxia and ischemic necrosis after surgical attempts. ${ }^{[3]}$

Herein, we report a case of ischemic necrosis of the medial side of the foot after posteromedial release of a resistant clubfoot case.

\section{CASE REPORT}

A three-year-old male patient was admitted to our hospital with bilateral neglected congenital foot

Received: October 19, 2021

Accepted: December 21, 2021

Published online: December 22, 2021

Correspondence: Celal Bozkurt, MD. Sağlık Bilimleri Üniversitesi, Gaziosmanpaşa Eğitim ve Araştırma Hastanesi, Ortopedi ve Travmatoloji Kliniği, 34255 Gaziosmanpaşa, istanbul, Türkiye.

E-mail: bozkurt.celal@gmail.com

Doi: 10.52312/jdrscr.2022.8

Citation: Bozkurt C, Karakurt O, Sepetçi Ö, Bal T, Sarıkaya B. Management of ischemic necrosis after posteromedial release of clubfoot. Jt Dis Relat Surg Case Rep 2022;1(1):23-26.

(02022 All right reserved by the Turkish Joint Diseases Foundation

(c) (1) (-) This is an open access article under the terms of the Creative Commons Attribution-NonCommercial License, which permits use, distribution and reproduction in any medium, provided the original work is properly cited and is not used for commercial purposes (http://creativecommons. org/licenses/by-nc/4.0/).

https://www.casereportsjointdrs.org

\section{ABSTRACT}

Some neglected and recurrent clubfoot may be treated surgically, particularly with posteromedial release. Due to the arterial deficiency in clubfoot, ischemic necrosis may be seen in case of posteromedial release. After surgery, plaster cast is applied and, therefore, the surgeon may not notice ischemia in the early period. Therefore, a few signs as purple hallux sign, pain and swelling and bullous lesions on the incision site are important signs of ischemia in the early postoperative period. Herein, we report a case of ischemic necrosis of the medial side of the foot after posteromedial release of a resistant clubfoot case.

Keywords: Arterial deficiency, clubfoot, ischemic necrosis, posteromedial release.

deformity. The patient could not walk and stand up, he was moving on his knees. The patient was not treated before. The deformity was idiopathic clubfoot bilaterally (Figure 1). There was no neurological deficit or any disease related to clubfoot. We evaluated the feet with the Priani scoring system. Using this scoring system, hind foot and midfoot are evaluated and scored. Posterior crease, empty heel, and equinus rigidity are evaluated for hind foot contracture. Medial crease, curvature of the lateral border and position of the head of the talus are evaluated for midfoot contracture. Each component may score $0,0.5$ or 1 . The Pirani score can be 0 to 6 . Six point represents the most deformed foot. In our case, the Pirani score was six, both feet were stiff. According to the preoperative color Doppler ultrasound (DUS), posterior tibial and dorsalis pedis arteries flow was sufficient and there was no retrograde flow.

At the first step, we applied conservative treatment according to Ponseti method. We manipulated the feet and applied cast for six weeks, but we could 

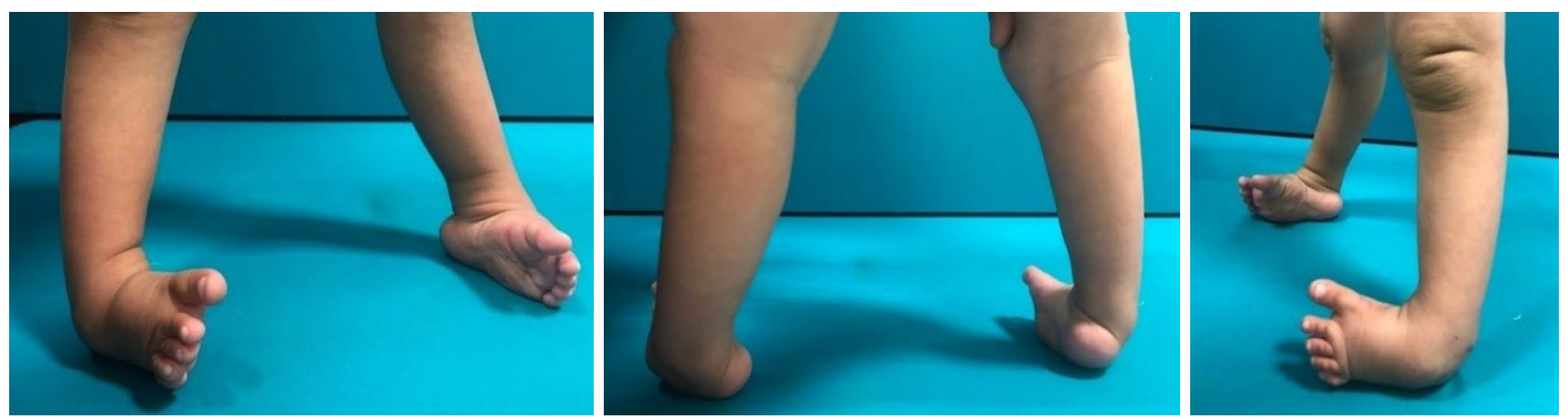

Figure 1. Neglected bilateral clubfoot.

not correct the deformity. We decided to correct the deformity surgically. We decided to release right side first and, then, release the left side after healing of the right side.

The patient underwent right foot posteromedial release under general anesthesia. The tourniquet was inflated after the extremity elevation, exsanguination was not applied. The posterior tibial, flexor digitorum longus, and flexor hallucis longus tendons were lengthened with $\mathrm{Z}$ lengthening. Talonavicular joint was reduced and stabilized with a pin. Before wound closure, the tourniquet was deflated and we checked the capillary refilling and posterior tibial and dorsalis pedis artery pulses. After wound closure, we examined the pulses and capillary refilling again. We found no circulation problem and applied long leg cast and the foot was positioned $30^{\circ}$ abduction and $10^{\circ}$ dorsiflexion.

On the postoperative Day 1, we made a window on the cast to change sterile dressings. There was no wound problem on the first day. By the second day, we detected cyanosis on the tip of the hallux (purple hallux sign) and the patient suffered from severe pain. Therefore, we removed the cast. There was swelling on the entire foot. On the dorsomedial side of the foot, there were bullous lesions and there was a cyanotic color change (Figure 2). According to color DUS posterior tibial artery was intact, but dorsalis pedis artery could not be detected due to the bullous lesions and excessive swelling. We changed the sterile wound dressing and, then, changed the foot position to $10^{\circ}$ plantar flexion and $10^{\circ}$ adduction to reduce the stretch on the medial side. We left the pin in place and placed the foot in a cast brace. Immediately, we initiated two broad-spectrum intravenous prophylactic antibiotics (third-generation cephalosporin and vancomycin), heparin, and vasodilator (nitroglycerin).

We changed the sterile dressings and sterilized the bullous lesions every day. There were no signs of infection. By the end of the first week, we observed a hypovascular ischemic area on the plantar surface
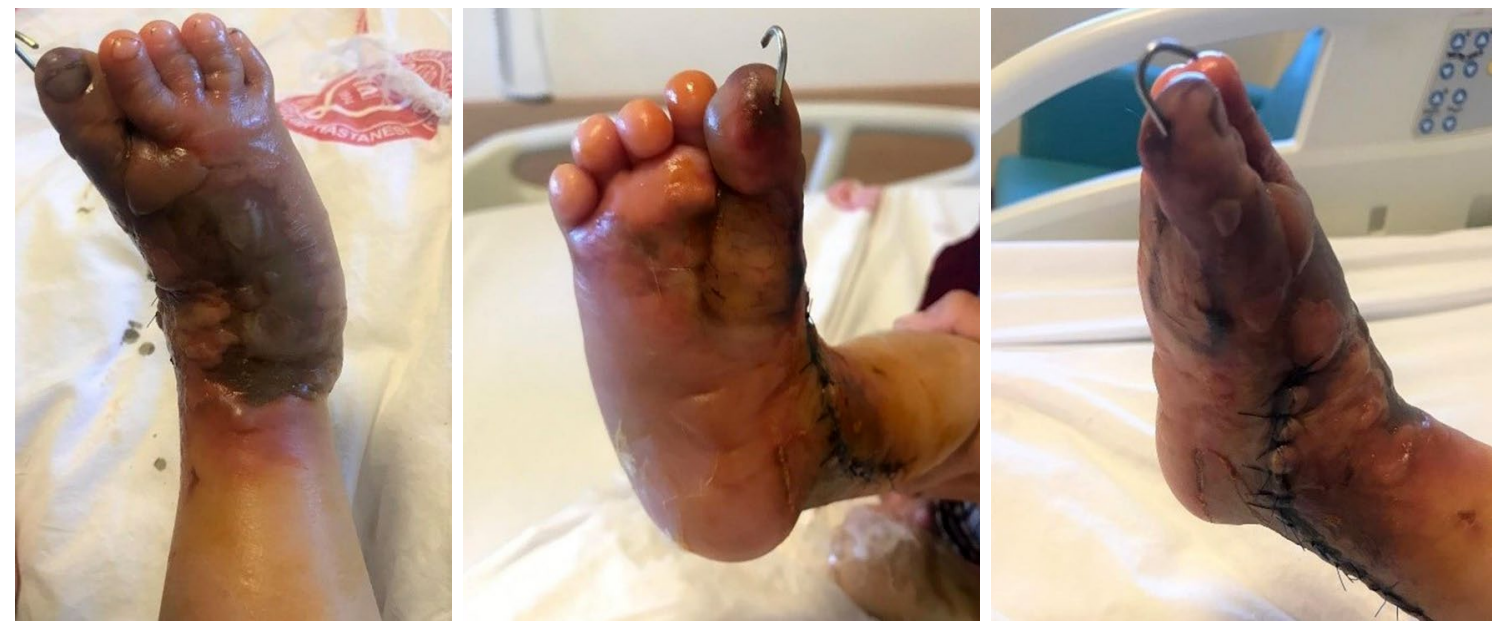

Figure 2. On Day 7, images showing cyanosis on the pulpa (purple hallux sign) of the hallux and hypovascular area on the plantar surface of the hallux. There were bullous lesions on the dorsomedial side of the foot. 

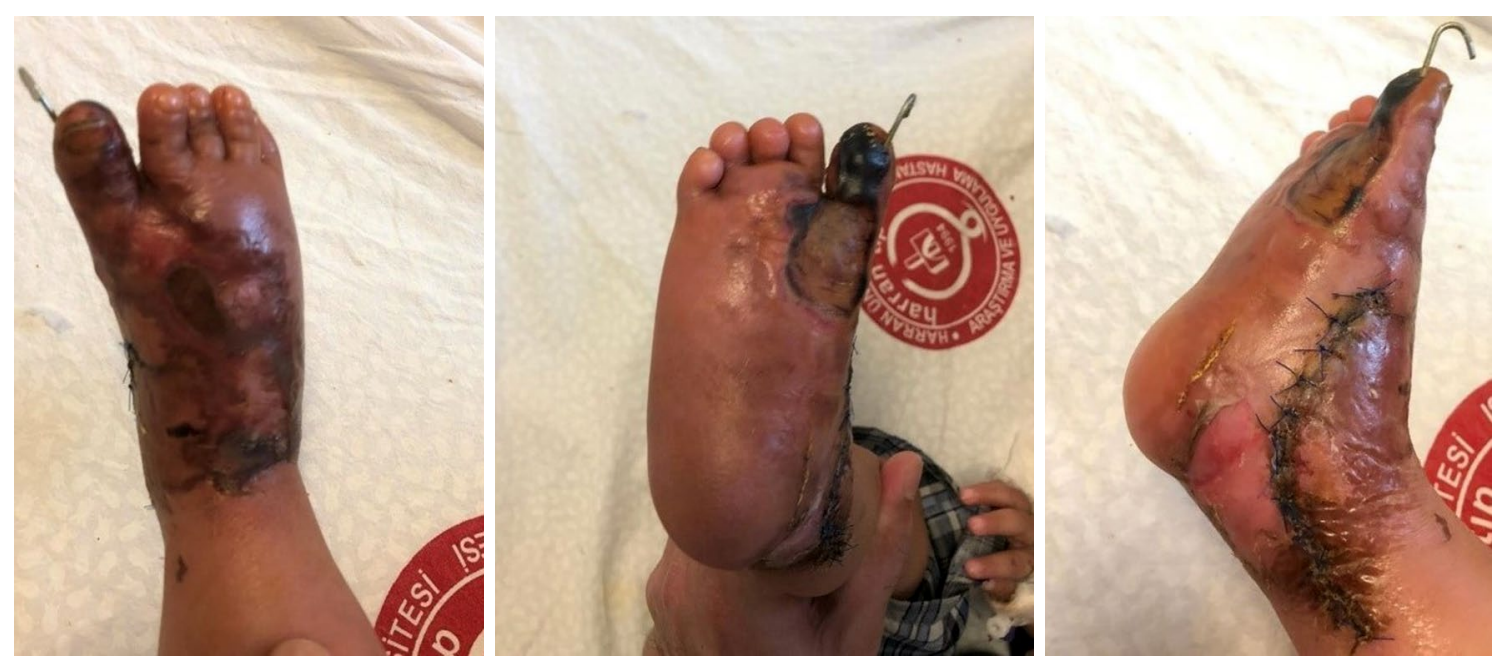

Figure 3. Pulpa of the hallux became necrotic. Swelling subsided and some wrinkles were seen around the incision site. Bullous lesions healed and the superficial cyanotic dorsal skin started to heal.
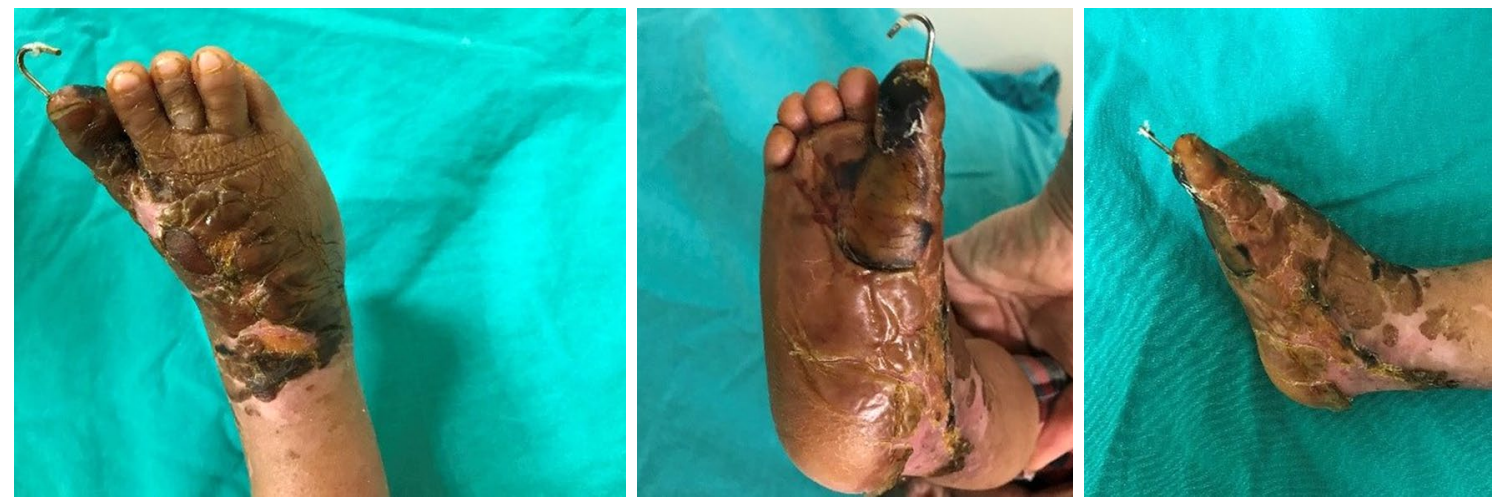

Figure 4. The bullous lesions and the cyanotic skin dried totally and we removed the plaster and the pin.

of the hallux starting from first metatarsal head (Figure 2). Cyanosis was more evident on the pulpa. At the end of the third week, there was a marked demarcation line around the hypovascular area and


Figure 5. There was skin sloughing and flexion deformity of the hallux. The necrotic and cyanotic lesions healed almost completely. the cyanotic area became necrotic (Figure 3). We did not perform any surgical attempts, and only observed the patient.

By the third week, swelling started to regress and the bullous lesions healed (Figure 4). At this stage, we discontinued the antibiotics and corrected the position of the foot and applied a long leg cast again. We observed the patient for one more week and, then, discharged at the end of the fourth week. Two weeks later, we removed the plaster and the pin at the end of the sixth week. At postoperative six weeks follow-up, skin sloughing at the plantar surface was observed and there was a minimal flexion contracture at the first metatarsophalangeal joint. The necrotic area and the hypovascular area healed almost completely and patient could stand on his foot plantigrade. By the postoperative fifth month, skin sloughing on the plantar surface of the first metatarsal ray was apparent, but all necrotic area was observed to be healed. The patient could stand 
on his plantigrade right foot (Figure 5). A written informed consent was obtained from the parents of the patient.

\section{DISCUSSION}

Cyanosis of the pulpa of the hallux, bullous skin lesions around the incision site and conspicuous pain were the early signs of hypoxia after posteromedial release surgery in our patient. Tibialis anterior and dorsalis pedis artery deficiencies may cause ischemic necrosis after major clubfoot surgeries. The foot is usually immobilized in a cast or splint after surgeries and, thus, it is difficult to see necrosis of the foot inside the cast. Therefore, signs such those presented in this report indicating risk of ischemic necrosis risk in the early period, are of critical importance.

Cast application after surgery and position of the foot in the cast may increase tissue hypoxia and ischemic necrosis in clubfoot treatment. ${ }^{[4]}$ David et al. ${ }^{[4]}$ reported that the cast did not have tourniquet effect and, thus, removal of the cast did not reverse or halt the necrotic process. Turko ${ }^{[5]}$ reported staged dorsiflexion after surgical treatment of resistant clubfoot to avoid tension necrosis. We positioned the foot $10^{\circ}$ dorsiflexion and $30^{\circ}$ abduction in the cast. Although the role of the cast in hypoxia is controversial, we removed the cast to also change the position of the foot. We applied a cast brace and controlled the foot daily to see the course of the bullous lesions and ischemic necrosis.

Removing the pin fixation in case of cyanosis is also a debate. ${ }^{[4]}$ We believe that, although pin fixation may exacerbate the hypoxia pin removal can be delayed until foot position correction and cast removal. If the ischemic appearance recovers and the hypovascular area is not too extensive, it may be better not to remove the pin, as there may be no other chance to correct the deformity.

Decreased arterial perfusion is a risk factor for surgical site infection, particularly at the first postoperative week, due to increased arterial demand. ${ }^{[6]}$ We initiated two broad-spectrum intravenous antibiotics, as we observed vascular compromise. We discontinued the antibiotics after the swelling and bullous lesions regressed. Intravenous heparin and vasodilator initiation may also be used to increase arterial perfusion, possibly improving the clinical progress. We initiated intravenous heparin and vasodilator immediately after observing the first signs of cyanosis. We also kept the foot warm and the extremity level with the heart.
Several authors have reported that the necrotic areas should be debrided and amputation may be need in selected cases. ${ }^{[4]}$ We share this view; however, we suggest that waiting can be beneficial, if there is no infection and, particularly if the necrotic area is not extensive. In our case, we observed that the hypovascular area including necrotic area completely healed at the end of five months postoperatively. However, there was skin sloughing on the hypovascular area due to devascularization and revascularization. The skin sloughing may cause functional limitation.

In conclusion, our case emphasizes that, after posteromedial release of clubfoot, foot should be closely observed for distal cyanosis, excessive incision site swelling and bullous lesions, as these lesions can indicate ischemic complications. In such cases, cast should be removed and position of the foot should be adjusted to relieve the medial side tension. Initiating intravenous prophylactic antibiotics, heparin and vasodilators should also be considered. Foot should be observed before pin removal, as it can be left in place unless removal is necessary. Surgical debridement may be delayed or relinquished completely, if there are no signs of infection.

\section{Declaration of conflicting interests}

The authors declared no conflicts of interest with respect to the authorship and/or publication of this article.

\section{Funding}

The authors received no financial support for the research and/or authorship of this article.

\section{REFERENCES}

1. Morcuende JA, Dolan LA, Dietz FR, Ponseti IV. Radical reduction in the rate of extensive corrective surgery for clubfoot using the Ponseti method. Pediatrics 2004;113:376-80.

2. Katz DA, Albanese EL, Levinsohn EM, Hootnick DR, Packard DS Jr, Grant WD, et al. Pulsed color-flow Doppler analysis of arterial deficiency in idiopathic clubfoot. J Pediatr Orthop 2003;23:84-7.

3. Shaheen S, Bahar MEH, Mohammed AHA, Elbadri SFA, Johari A. Arterial tree anomalies in patients with clubfoot: An investigation carried out at Soba University Hospital. J Pediatr Orthop B 2018;27:67-72.

4. David RH, Packard DS Jr, Levinsohn EM, Berkowitz SA, Aronsson DD, Crider RJ Jr. Ischemic necrosis following clubfoot surgery: The purple hallux sign. J Pediatr Orthop B 2004;13:315-22.

5. Turco VJ. Clubfoot (Current problems in orthopaedics). New York: Churchill Livingstone; 1981.

6. Hootnick DR, Packard DS Jr, Levinsohn EM, Crider RJ Jr. Confirmation of arterial deficiencies in a limb with necrosis following clubfoot surgery. J Pediatr Orthop B 1999;8:187-93. 